\title{
'Recado a Victoria Ocampo, en la Argentina', de Gabriela Mistral
}

\author{
'Letter to Victoria Ocampo, in Argentina' by Gabriela Mistral
}

Cedomil Goić

Domingo F. Sarmiento Emeritus Professor, The University of Michigan, USA

Correo electrónico: cgoic@vtr.net

\begin{abstract}
"Recado a Victoria Ocampo, en Argentina" es una carta poética mixta. La hospedada escribe haciendo el elogio del lugar y de la casa donde se hospeda. Una casa que le parece hecha a semejanza de su dueña. Hace el elogio de los alimentos, de la tierra, de la madre que ama y juega con sus hijos. Agradece el grato descanso que le brindó su casa, el jardín, el canto de las aves, el verde, el aire del mar y su generosa acogida de escritores de todo el mundo. Hace la alabanza de la grandeza moral y física de su huésped, semejante a la del territorio argentino. Finalmente, se despide y le encarga la América entera, que es grandiosa como ella, la libertad, la educación popular, la danza y el canto y la vida, con su dolor y su dicha. Lo pide por lo que más quiera: por la tradición de la tierra, su historia, la sangre, por Martín Fierro, San Martín y Jesucristo.
\end{abstract}

Palabras clave: Gabriela Mistral (1889-1957), Victoria Ocampo (1890-1979), Argentina, "recado", carta, partes de la epístola.

"Letter to Victoria Ocampo, in Argentina" is a poetic letter, a mixed epistle. A letter written by a personal guest to her wellcoming hostess praising the natural place as well as her house, made at the image of the hostess. She thanks for the opportunity to enjoy the house, the food, the garden, the singing birds, the green, the air, and her generous wellcome of writers coming from all places of the world. She praises the moral and physical greatness of her friend and hostess resembling the natural landscape of the nation. In a final farewell, she says goodbye and asks her hostess to look out for America, and the freedom, the education, the natural, the historical and the cultural patrimony of Argentina, in the name of Martín Fierro, San Martín and Jesus Christ.

Key words: Gabriela Mistral (1889-1957), Victoria Ocampo (1890-1979), Argentina, "recado" (letter, message), parts of the epistle.

\section{INTRODUCCIÓN}

"Recado a Victoria Ocampo, en la Argentina", de Gabriela Mistral es el poema que cierra la sección "Recados", la última sección del libro Tala (1938), que contiene seis epístolas en verso: "Recado de nacimiento para Chile", "Recado a Lolita Arriaga, en México", "Recado para las Antillas", "Recado a Rafaela Ortega, en Castilla", 
"Recado para la 'Residencia de Pedralbes', en Cataluña", además del recado para Victoria Ocampo. El primero es carta de respuesta a un amigo por el anuncio del nacimiento de una niña. Dos de ellos remiten a lugares y la celebración del día de la niña en las Antillas y el recuerdo gozoso de la casa durante su estancia en la Residencia de Pedralbes. Otros tres poemas son panegíricos y tienen por destinatarias a tres mujeres: Lolita Arriaga, en México, Rafaela Ortega, en Castilla, y Victoria Ocampo, en Argentina.

Cuatro de ellos están compuestos en verso libre de arte mayor, otro en cuartetos endecasilábicos de rima romanceada -a-a, y uno de versos eneasilábicos de rima romanceada -í-a. Más tarde, en Lagar (1954), incluirá otro poema del mismo género: el "Recado terrestre", en versos endecasílabos sueltos, que aparece también en una sección final, inmediatamente antes de "Epílogo". De todos ellos, "Recado a Victoria Ocampo, en Argentina" es la misiva más directa y familiar.

Entre sus inéditos, se cuenta el poema titulado "Recado para Alfonso Reyes" (Mistral, Reino, 1983), en versos octosílabos y rima romanceada, carta de excusa.

\section{¿QUÉ ES UN RECADO?}

Recado es expresión que va más allá de "mensaje o respuesta que de palabra se da o se envía a alguien" (DRAE). Gabriela Mistral designa con esta palabra dos géneros diferentes. Por una parte, los artículos periodísticos, crónicas o ensayos en prosa que escribió en gran cantidad y, por otra, muy particularmente, las originales epístolas escritas en verso o cartas poéticas que se suman con su novedad inconfundible a una larga tradición latina, hispánica e hispanoamericana.

En una determinación metapoética, los "Recados" son definidos de la siguiente manera en los Notas finales del libro Tala (1938):

Las cartas que van para muy lejos y que se escriben cada tres o cinco años, suelen aventar lo demasiado temporal -la semana, el año- y lo demasiado menudo -el natalicio, el año nuevo, el cambio de casa-. Y cuando, además, se las escribe sobre el rescoldo de una poesía, sintiendo todavía en el aire el revoloteo de un ritmo sólo a medias roto y algunas rimas de esas que llamé entrometidas, en tal caso, la carta se vuelve esta cosa juguetona, tirada aquí y allá por el verso y por la prosa que se la disputan.

Por otra parte, la persona nacional con quien se vivió (personas son siempre para mí los países) a cada rato se pone delante del destinatario y a trechos lo desplaza. Un paisaje de huertos o de caña o de cafetal, tapa de un golpe la cara del amigo al que sonreíamos; un cerro suele cubrir la casa que estábamos mirando y por cuya puerta la carta va a entrar llevando su manojo de noticias.

Me ha pasado esto muchas veces. No doy por novedad tales caprichos o jugarretas: otros las han hecho y, con más pudor que yo, se las guardaron. Yo las dejo en los suburbios del libro, fuora dei muri, como corresponde a su clase un poco plebeya o tercerona. Las incorporo por una razón atrabiliaria, es decir, por una loca razón, como son las razones de las mujeres: al cabo, estos recados llevan el tono más mío, el más frecuente, mi dejo rural en el que he vivido y en el que me voy a morir.

La Nota permite distinguir tres rasgos principales que Gabriela Mistral hace suyos en esta definición. Primero, el recado desplaza la carta familiar frecuente de noticias o informaciones sobre hechos particulares o incidentales y la referencia a tiempos 
muy definidos, en favor de cartas que se escriben a distancia del destinatario "cada tres o cinco años", debe entenderse, de hechos de mayor trascendencia y significación general eliminando lo anecdótico. Seguidamente, apunta su distanciamiento de la epístola poética tradicional y su metro regular -generalmente tercetos endecasílabosmientras, cuando se trata del recado poético, lo escribe en verso libre de ritmo roto a medias y de rimas entrometidas, externas e internas, mezclado con el coloquialismo -el antiguo sermo de la epístola- propio de la carta familiar, esta se vuelve esta cosa juguetona 'tirada aquí y allá por el verso y por la prosa que se la disputan", marcada por la oralidad y por su carácter híbrido. Esta cercanía a la lengua hablada es en Gabriela Mistral un fenómeno singularmente marcado -"la costa a que me trajiste", "te digo adiós y aquí te dejo", "te quiero porque eres vasca, y eres terca y apuntas lejos", etc. etc.- ilustran, entre otros rasgos, la oralidad de este poema.

Por otra parte, su experiencia de vida en diversos países le lleva a confundir naciones y personas metaforizando sus figuras. Nación o persona nacional: México, Castilla, Cataluña, Argentina, y sus paisajes, huertos, cerros, mediante lo que llama un capricho o jugarreta, desplaza la figura del/la destinatario/a. El país o el paisaje se hacen personas, las personas se hacen país o paisaje.

Mirado con humor, por último, este juego mezclado la lleva a dejar los recados "en los suburbios del libro, fuora dei muri", por un lado, como la sección final del libro; por otro, como un género marginal. A pesar de todo, los incorpora por una loca razón: "como son las razones de las mujeres-: al cabo, estos recados llevan el tono más mío, el más frecuente, mi dejo rural en el que he vivido y en el que me voy a morir". Habla de su "dejo rural", es decir, de la transfiguración del lenguaje, de la sintaxis, del léxico y del temple de ánimo que lo caracteriza.

La representación o retrato de Victoria Ocampo tiene en Gabriela Mistral, además, un recado en prosa sobre "Victoria Ocampo" (febrero de 1942)1, quien escribió tal vez uno de sus ensayos más notables con una elaborada caracterización de la escritora que confirma los rasgos físicos y morales del retrato de la escritora en el recado poético de unos años antes.

Victoria Ocampo conoció a Gabriela en 1930, en Madrid. Ella cuenta cómo en el primer encuentro Gabriela le reprochó que hubiera nacido en la más cosmopolita de las ciudades de Sudamérica, que fuera tan afrancesada y que hubiese ignorado a Alfonsina Storni. Tenían un año de diferencia y a esa fecha una tenía 47 y la otra 48 años de edad. Se encontraron todavía algunas veces más. En plan de caracterización de la escritora argentina de ella dice:

"En Victoria ha de haber muchas Victorias, pues yo me conozco cuando menos cuatro... Una es la ahijada de Francia, que se saben todos -oraciones, rondas y cuentos de hadas recibidos de la aya francesa que escamoteaba el habla criolla...

"Y hay al costado acá de esta fiel al Sena y a Racine, una "advertida" de que el Sena no vale para todas las cosas -por ejemplo- para el viento fuerte de la aventura y para cierta frescura de las instituciones a causa de haberse vuelto el pobre, parisianamente, urbe nueva. Esta Victoria que hace la escapada hacia el canal, llega al otro lado y se aposenta en la

\footnotetext{
${ }^{1}$ Gabriela Mistral. Gabriela Mistral piensa en... Selección y prólogo de Roque E. Scarpa. Santiago: Editorial Andrés Bello, 1978. pp. 49-56.
} 
orilla diez veces opuesta, por gana de la ráfaga del canal o de la mediterránea, más otras dádivas que se reciben allí y sólo allí: una poesía menos metida en la carne y una prosa más permeada de música y por allí de gracia. Y detrás de estas dos Victorias de mente prestada a la extranjería, detrás de estas dos grandes veleidades, que unos le tienen por vicio y otros por niñerías, una formidable argentinaza que, en cuanto tira ese espejo en que se mira y se desfigura a todo gusto, se nos quedan los suyos, en la más radical y desusada argentinidad, riéndose de los que les creímos las jugarretas y como diciendo: -¿Qué te figurabas? ¿Creías, gran boba, que se puede tener una Pampa de esta anchura y este vigor y un río como el Plata, y se puede vivir con el Martín Fierro sesteando bajo el sesgo y no llevarlo en el alma tanto como se les carga en el cuerpo? ¿Tú crees que se camina con este paso largo de lebrel y se respira con este cuello de llama y se gozan estas dunas inacabables, siendo del Loire y soñando Piccadilly?" (49).

Y más adelante:

"Y esta Victoria va a ser la que se queda después del rasgón, hecho en la hiedra o la buganvilia europea y nos queda delante la piedra desnuda, el bloque terco e íntegro de una argentinidad maciza, que parece que nunca fue desmoronado de su cantera: queda la mujeraza del Río de la Plata, y en adelante, aunque os digan esto y aquello ya no veréis sino a esta fiel, hecha a imagen y semejanza de su geografía. Nadie os hará creer más en las Victorias de los espejos enhollinados o fraudulentos" (50)

Y un último rasgo, para Gabriela Mistral el más preocupante es el siguiente:

"Esta Victoria criolla es dueña de todas las holguras y desenvolturas que dan el nombre y la riqueza para vivir, y sin embargo, ella es hasta tímida consumada para lo que nos es el vivir, para lo que es el decir (ella dice "expresarse"), para derramar su rica médula humana sobre un papel. ¡Parece defenderse con su verbo, y su verbo bastaría como dato mental!" (50)

El marco de referencia a que apunta la situación de la enunciación es su estancia durante ocho días, en el mes de abril, en Villa Victoria, Mar del Plata, casa de verano de la escritora, durante la Semana Santa de 1938. Hay un efecto de poema postal en el que el texto tiene al dorso una referencia gráfica. Existen fotografías de Villa Victoria que muestran el frente de la casa, algunos ángulos y sus jardines y tenemos su dirección en el barrio Divino Rostro, calle Matheu 1851, Mar del Plata, donde hoy día, rescatada como un monumento, funciona el Centro Cultural Villa Victoria Ocampo.

\section{CUMPLEAÑOS}

Entre las referencias que enmarcan exteriormente la producción del poema está la celebración, el 7 de abril, del cumpleaños de Victoria Ocampo, fecha de nacimiento que ambas compartían. Es con motivo de esta celebración que Gabriela Mistral escribe este recado.

Durante la estadía de Gabriela Mistral en Villa Ocampo, ambas escritoras se enviaban mensajes de una habitación a otra. Es lo que la escritora argentina llamará "cartas habladas", pues "una carta que va de un piso a otro de una casa tiene forzosamente que ser diferente de una composición literaria del género epistolar, como un pájaro vivo de uno embalsamado" ("Gabriela Mistral en sus cartas”, 64-65). De 
esos mensajes se han conservado tres de Gabriela Mistral, mientras los de Victoria Ocampo están perdidos. Gabriela Mistral estaba acompañada de Consuelo Connie Saleva, secretaria y amiga portorriqueña que la acompañara en Francia, California, USA, México, Brasil y Argentina. Coincidió con la presencia de María Rosa Oliver, entre otras. Varias personas alojaban en la casa simultáneamente -la casa tenía once habitaciones-, aunque su dueña estuviera enferma.

Era el tiempo de las pruebas de imprenta de la primera edición de Tala que publicará Sur, en 1938. Gabriela habla de "Nocturno del descendimiento" que ha dedicado a Victoria, pero debe entenderse que el último poema del libro es el "Recado a Victoria Ocampo, en la Argentina”, poema de despedida, en agradecimiento y correspondencia por su hospitalidad y como saludo del cumpleaños.

\section{RECEPCIÓN}

La escritora argentina recuerda de la siguiente manera aquella fecha, aunque equivoca el año. Se trata de 1938 y no de 1937 :

"Pasó en Mar del Plata el 7 de abril de 1937. Era el día de su cumpleaños. Lo compartíamos, pero sólo descubrimos la coincidencia entonces. Bajé temprano a desearle la felicidad que acostumbramos a desear en fechas fijas, como pidiendo prórroga. Estaba sentada en la cama, lápiz en mano, corrigiendo algo. "¿Qué has escrito?”, le pregunté. "Un recado para ti, para el día de tu santo, como le llamas."

¿Puedo leer?”

Victoria, la costa a que me trajiste, tiene dulces los pastos y salobre el viento, el mar Atlántico como crin de potros

Te digo adiós y aquí te dejo,

45 como te hallé, sentada en dunas.

Guarda libre a tu Argentina el viento, el cielo y los trojes; libre la Cartilla, libre el rezo, libre el canto, libre el llanto.

"En 1937, en la mañana que olía a pan tostado, el pedido de guardar libres a mi Argentina, a la cartilla y al rezo, aunque extravagante no me sorprendió por venir de Gabriela. Ella, la tan viajera, tenía temor de que yo pudiera irme definitivamente del país y quería a todo trance impedírmelo. Con ese fin intentaba persuadirme de que mi presencia en Argentina era necesaria. Por eso, en su poema me encargaba tierras de América. Más tarde, llegó un momento en que quiso arrancarme precipitadamente de estas tierras. Quizá se sintió en parte responsable (cosa totalmente equivocada) de mi no querer abandonarlas cuando la cartilla y el rezo no eran libres. Pero aunque no me extrañó el pedido del Recado (que se anticipaba) me pareció, eso sí, nacer de la más desenfrenada fantasía. Todo pensé, menos que el final de ese poema escrito el día 
de "nuestro santo" podía ser profético, que nuestra Argentina podía estar realmente amenazada, que para guardarle la libertad, íbamos a tener que sacrificarle la nuestra, por lo menos, la personal y material (la otra, ¿quién nos la quita?). El tono del pedido era grave y urgente, como cuando nos dicen por lo que más quieras.

Por la Ley vieja de la Tierra;

por lo que es, por lo que ha sido,

60 por tu sangre y por la mía, ipor Martín Fierro y el Gran Cuyano*

y por Nuestro Señor Jesucristo!

"Pero el 7 de abril de 1937 yo no sabía que el poema escrito por Gabriela, el poema del día de "nuestro santo", el de los siete niños, los médanos, las torcazas, y el Dios tremendo, era una profecía.

Y ella tampoco sabía que yo no lo sabía."

$\ldots$

-"para celebrar la fecha y la coincidencia, me dedicó el poema que acabo de citar, cuyo original, escrito con lápiz, lo guardé tan bien que ahora lo he perdido... Me dio el poema como si me estuviera ennobleciendo. Aparte del placer, qué alivio fue."

("Y Lucila le hablaba a río", La Nación (Buenos Aires, 3 de marzo, 1957)

Bajo la dictadura de Juan Domingo Perón, Victoria Ocampo fue detenida en prisión y liberada solamente en 1953, por efecto de un cable dirigido por Gabriela Mistral al dictador y la intervención de Jawaharlal Nehru. En 1957, Victoria Ocampo vio a Gabriela en Estados Unidos, cuando ésta ya no podía verla.

EL POEMA

"Recado a Victoria Ocampo, en Argentina" es un poema de 62 versos, ordenados en nueve grupos estróficos de 7, 8, 5, 6, 9, 8, 7, 7 y 5 líneas; escrito en verso libre de 6 a 14 sílabas, con distantes y ocasionales rimas asonantes en -a-a, -a-o, -e-a, -e-o, -i-a, -i-o, -o-a, -o-e, -o-o, y múltiples rimas internas. La edición de Editorial Sur del poema fue modificada felizmente en unas pocas líneas en la edición de 1947 de Editorial Losada. La edición de Editorial Losada, en todas sus colecciones, cae en la errata de pasos por pastos, en el segundo verso del poema.

\section{PARTES DEL RECADO}

El recado poético, "Recado a Victoria Ocampo, en Argentina", como otros de sus recados poéticos, pertenece al género de la carta panegírica, elogio de la gran escritora argentina Victoria Ocampo (1890-1979).

\section{MATRIZ Y MODELO}

La matriz del texto poético es la alabanza de Victoria Ocampo y es al mismo tiempo el elogio del paisaje y de Villa Victoria, la casa de verano en Mar del Plata de Victoria Ocampo, a cuya semejanza aparece hecha. 
Victoria, sin más agregados, es el apóstrofe con que se la saluda (salutatio), seguido del tú de amistad, ternura y confianza, a la destinataria de la carta. Términos de cercanía, y afecto, rasgos que se extenderán en la hipervaloración de paisaje y casa. La costa, el mar Atlántico, el ganado -en una hermosa imagen comparativa cruzada de lo marino y lo animado -AB/BA: el mar Atlántico como crin de potros / y los ganados como el mar Atlántico- "y tu casa", con flores, hierros y maderas, "conversación, lealtad y muros". Nota esta última que remite a la separación de huéspedes y señora de la casa y al orden, la protección, la seguridad, y la disciplina cortés.

\section{MODELO Y AMPLIFICACIÓN}

Los versos 1 a 7, el primer grupo estrófico, constituyen el modelo del texto poético, que será ampliado en las estrofas siguientes.

Están allí los componentes integradores del paisaje que reúne los términos opuestos, del gusto, de lo dulce y lo salobre, y el mar y sus olas y los ganados numerosos, partícipes de la inmensidad de su extensión. Y la casa que concierta la belleza y los aromas con la sólida autenticidad de lo material -hierros y maderas y muros- así como de lo espiritual: conversación y lealtad:

Victoria, la costa a que me trajiste, tiene dulces los pastos y salobre el viento, el mar Atlántico como crin de potros y los ganados como el mar Atlántico.

$5 \mathrm{Y}$ tu casa, Victoria, tiene alhucemas, y verídicos tiene hierro y maderas, conversación, lealtad y muros.

\section{LA CASA}

La amplificación (amplificatio) dará lugar en ésta y las estrofas siguientes a una descripción (descriptio) de los rasgos de casa y persona, dignos de elogio y alabanza, que tienen que ver, primero, con la construcción y las dimensiones de la casa, hecha a imagen de Victoria y no de medidas convencionales. Luego, como una réplica-vainade su cuerpo, hija y madre a la vez. Estructura de paz y sueño, que le dio puertas para abrir y cerrar, y umbral que la acoge y espera:

Albañil, plomero, vidriero, midieron sin compases, midieron mirándote,

10 midieron, midieron...

Y la casa, que es tu vaina, medio es tu madre, medio tu hija... Industria te hicieron de paz y sueño; puertas dieron para tu antojo;

15 umbral tendieron a tus pies...

Esta es una primera espacialización de lo humano y una humanización del espacio material, una identificación de casa y persona. 


\section{ALIMENTOS}

La hablante que goza de su hospitalidad elogia el pan y la fruta, el vino y la leche, con doble sobrepujamiento. Mujer "terrestre", por estar ligada a la tierra, no mera terrateniente, en la totalidad de sus manifestaciones, cultivos y procesamientos finales: "de la mano a la mano/con espiga y horno, cepa y lagar":

Yo no sé si es mejor fruta que pan

y es el vino mejor que la leche en tu mesa.

Tú decidiste ser "la terrestre", y te sirve la Tierra de la mano a la mano,

20 con espiga y horno, cepa y lagar.

Ser la "terrestre", significa ahora una identificación de la mujer y la Tierra, una Demeter o Ceres argentina ${ }^{2}$.

\section{VICTORIA Y SUS SIETE HIJOS}

Elogia casa y jardín y en ellos a la madre y a sus siete hijos que llenan su vida de juego y alegría, enredada con ellos y dejándose caer en los pastos y en las arenas o médanos platenses:

La casa y el jardín cruzan los niños; ellos parten tus ojos yendo y viniendo; sus siete nombres llenan tu boca, los siete donaires sueltan tu risa

25 y te enredas con ellos en hierbas locas o te caes con ellos pasando médanos.

Imagen de la Madre de una suma mágica de hijos, madre vigilante, alegre y juguetona.

\section{AGRADECIMIENTOS}

Manifiesta, en seguida, en una serie enumerativa anafórica, la gratitud por muchas cosas: por el verdadero disfrute del sueño que le brinda la casa, y las sensaciones del abrigo y el suave roce de mantas de lana merino, por las rojas flores del ceibo, por el canto mañanero de las torcazas, y de las aves atraídas por la "fuente de pájaros", por el verde de la naturaleza toda, que da descanso y alivio a sus ojos heridos, por el aroma salino del viento y por su acogedora relación con los numerosos escritores de todos los extremos del mundo, que invitados por ella habitaron su casa. El número considerable de ellos y la variedad de sus orígenes la llevan a la exageración cuantitativa -una locura- cuarenta en lugar de cuatro puntos cardinales:

\footnotetext{
${ }^{2}$ Esta asimilación del cuerpo al territorio argentino y americano se parece a la identidad de la destinataria explícita de la novela de Eduardo Mallea, La bahía de silencio (Buenos Aires: Editorial Sudamericana, 1940).
} 
Gracias por el sueño que me dio tu casa, que fue de vellón de lana merino; por cada copo de tu árbol de ceibo, por la mañana en que oí las torcazas; por tu ocurrencia de "fuente de pájaros",* por tanto verde en mis ojos heridos, y bocanada de sal en mi aliento: por tu paciencia para poetas

35 de los cuarenta puntos cardinales...

\section{DECLARACIÓN DE AFECTO}

En correspondencia con todo ello, manifiesta su afecto a Victoria por muchas razones: por su origen, con quien se identifica; por su carácter o temperamento, de lo étnico o heredado a lo por venir; y porque se parece a lo natural americano: al maíz, que inunda el continente, y llena la mano y la boca, y se parece a la Pampa dominada por el viento y el alma que es el misterio divino, la razón cristiana de América. Esto es, corresponder, -“pagar con igualdad, relativa o proporcionalmente, afectos beneficios o agasajos" (DRAE). Pone de este modo el tono positivo, afín, afectuoso y conmovido por la admirable personalidad de la huésped en un grado de intensidad abierto y declarado con el acento puesto en el incremento dimensional: abundancia y extensión superlativa como espacialización suma de la imagen de la mujer o su representación, por su parecerse a 'bultos naturales': al maíz abundante, a la Pampa que solo el viento domina y el alma grande y divina.

Lo representado es dicho, pero más que nada expresado; primero, como virtud específica de amor y gratitud, ternura y admiración, sin reparos -terca es virtud, vale por tenaz y decidida-; pura positividad y positividad intensa marcada por la dimensionalidad, la grandeza, la gracia y el juego alegre y maternal de la mujer; como implícita gratitud por la acogida, el descanso dulce y hermoso:

Te quiero porque eres vasca y eres terca y apuntas lejos, a lo que viene y aún no llega; por tus esperanzas y porque te pareces a bultos naturales:

40 a maíz que rebosa la América rebosa mano, rebosa boca-, y a la Pampa que es de su viento y el alma que es del Dios tremendo...

\section{DESPEDIDA Y ENCARGOS}

Con esta alta intensidad se despide-valedictio-, "Te digo adiós y aquí te dejo", a la hora de partir de su tierra encargando o encomendando a la mujer dimensionalmente grande y gigantesca como la naturaleza y el país argentino -ceiba, flamenco, andina y fluvial, Río de la Plata, la Pampa, y las tierras de América-, como tarea dominante. Este es el mundonovismo espacial ensoñado por la Mistral que con la misma marca dimensional le solicita el cuidado de las tierras de América en nuevos términos de 
modos espaciales: "a ti tan ceiba y tan flamenco, tan andina y tan fluvial, y tan cascada cegadora, y tan relámpago de la Pampa”.
Te digo adiós y aquí te dejo,
45 como te hallé, sentada en dunas.
Te encargo tierras de la América, ¡a ti $\tan$ ceiba y $\tan$ flamenco, y tan andina y tan fluvial
y tan cascada cegadora
50 y tan relámpago de la Pampa!

Por último, le encarga o pide -petitio-, final y consecuentemente, que asuma, grande y poderosa, las tareas que cuiden de la libertad de su país, su naturaleza y su agricultura, así como de la educación popular, la religión, el canto y la danza, el mundo del gaucho y la vida-dolor y dicha- de todo ser humano:

Guarda libre a tu Argentina el viento, el cielo y los trojes; libre la Cartilla, libre el rezo, libre el canto, libre el llanto.

55 el pericón y la milonga, libre el lazo y el galope iy el dolor y la dicha libres!

Para concluir, pone las razones múltiples -americanas y cristianas- que habrán de moverla, "por lo que más quieras" como dirá Victoria -argumentatio-: por amor a la tierra, a la tradición, por la herencia americana, india y occidental, por Martín Fierro, el gaucho dolorido, por José de San Martín, el Libertador, y por Nuestro Señor Jesucristo:
Por la Ley vieja de la Tierra;
por lo que es, por lo que ha sido,
60 por tu sangre y por la mía, ipor Martín Fierro y el Gran Cuyano* y por Nuestro Señor Jesucristo!

\section{EN SUMA}

"Recado a Victoria Ocampo, en Argentina" es carta mixta de alabanza y admiración, de amistad, de agradecimiento, de elogio de las cosas y carta de petición. Quien escribe es la hospedada agradecida y llena de amor por la admirable mujer a quien alaba por sus virtudes y elogia por sus cosas, mezclando, afecto, admiración, gratitud y esperanza de grandeza. Todo en un tono de virtudes específicamente afectivas, cardíacas, en grado positivo y magnificador de considerable intensidad. A quien escribe es a su generosa huésped, en agradecimiento por su amistad, por sus atenciones y por su hospitalidad. A una mujer a quien ve como la imagen de la casa, del campo y del país, en un juego de dimensiones físicas - mujer grande, bultos naturales, país extenso, continente americano- y morales -terca, vasca, maternal y lúdrica. Escribe sobre la grandeza moral y física de la elogiada, sobre el eco de la naturaleza en su 
figura, réplica del entorno grandioso y perfumado. Entre las cosas externas, pondera la casa, imagen de su cuerpo, el cuerpo, los alimentos, el jardín y los hijos. Le encarga el cuidado de la libertad de la Argentina y de sus bienes naturales y culturales. Entre las cosas internas: le agradece el goce del descanso y del sueño, por la belleza del jardín y del paisaje. El poema rescata definitivamente a la terrestre, a la mujer vinculada y reconocible en la tierra argentina y americana, cuyas virtudes intelectuales la hacen digna de altas tareas y responsabilidades históricas y culturales en nuestro mundo. Al mismo tiempo, posterga la extranjería, que le reprochaba en el primer encuentro de 1930, para ponderar los rasgos físicos, morales e intelectuales de su autoctonía, enriqueciendo con nuevos rasgos su compleja imagen personal en la que se unen fuerza y timidez, tierra y escritura.

\section{OBRAS CITADAS}

Goić, Cedomil. 1999. “Gabriela Mistral, 'Recado terrestre'”. Taller de Letras 27: 9-22.

Iglesias, Augusto. 1950. Gabriela Mistral y el modernismo en Chile. Ensayos de crítica subjetiva. Santiago: Editorial Universitaria, $452 \mathrm{p}$.

Meyer, Doris. 1990. Victoria Ocampo. Against de Wind and the Tide. Austin, Texas: The University of Texas Press, $314 \mathrm{p}$.

_. 1996. "La correspondencia entre Gabriela Mistral y Victoria Ocampo: reflexiones sobre la identidad americana", Taller de Letras. Número especial: 87-100.

Mistral, Gabriela. 1938. Tala. Poemas. Buenos Aires: Sur.

Mistral, Gabriela. 1946. Tala. Poemas. Buenos Aires.

Mistral, Gabriela. 1954. Lagar. Santiago: Editorial del Pacífico.

Mistral, Gabriela. 1966. Poesías completas. Madrid: Aguilar.

Mistral, Gabriela. 1983. Reino. Valparaíso: Ediciones Universitarias de Valparaíso.

Mistral, Gabriela. 2008. Amasijo. Santiago: Ediciones Universidad Católica.

Mistral, Gabriela. 1978. "Victoria Ocampo", Gabriela Mistral piensa en... Selección y prólogo de Roque E. Scarpa. Santiago: Andrés Bello: 49-56; en La tierra tiene la actitud de una mujer. Selección y prólogo de Pedro Pablo Zegers. 1998 Santiago: RIL editores, 1998: 243249. Tb. en Antología Mayor. 1992. Santiago: Editorial Cochrane.

Mistral, Gabriela y Victoria Ocampo. 2007. Esta América Nuestra. Correspondencia 19261956. Introducción y notas de Elizabeth Horan y Doris Meyer. Buenos Aires: El Cuenco de Plata Latinoamericana, $352 \mathrm{p}$.

Ocampo, Victoria. 1935. Supremacía del alma y de la sangre. Buenos Aires-Madrid: 57 p.

Ocampo, Victoria. 1963. "Gabriela Mistral en sus cartas", Testimonios. Sexta serie (1957-1962). Buenos Aires: Sur, 59-82. Repr. parcialmente en Efraín Szmulewicz. 1974. Gabriela Mistral (Biografía emotiva). Santiago: Editorial Orbe, pp. 86-90.

Ocampo,Victoria. 1957. "Y Lucila le hablaba a río", La Nación (Buenos Aires, 3 de marzo); Sur 245 (Marzo-abril 1957): 75-82.

Salomone, Alicia N. 2000. "Identidades en el espejo. Diálogos entre Gabriela Mistral y Victoria Ocampo", Universum 15: 241-256. Tb. en 2000. CELEHIS. Revista del Centro de Letras Hispanoamericanas 9: 309-334. Recogido en Alicia N. Salomone et al. 2004. Modernidad en otro tono. Escritura de mujeres latinoamericanas. 1920-1950. Santiago: Editorial Cuarto Propio, 285 p.

Szmulewicz, Efraín. 1974. Gabriela Mistral (Biografía emotiva). Santiago: Editorial Orbe, pp. 86-90. 


\section{GABRIELA MISTRAL}

\section{RECADO A VICTORIA OCAMPO, EN LA ARGENTINA}

Victoria ${ }^{3}$, la costa a que me trajiste ${ }^{4}$, tiene dulces los $\operatorname{pastos}^{5}$ y salobre el viento, el mar Atlántico como crin de potros y los ganados como el mar Atlántico.

5 Y tu casa, Victoria, tiene alhucemas, y verídicos tiene hierro y maderas, conversación, lealtad y muros.

Albañil, plomero, vidriero, midieron sin compases, midieron mirándote,

10 midieron, midieron...

Y la casa, que es tu vaina, medio es tu madre, medio tu hija... Industria te hicieron de paz y sueño; puertas dieron para tu antojo;

15 umbral tendieron a tus pies...

Yo no sé si es mejor fruta que pan y es el vino mejor que la leche en tu mesa. Tú decidiste ser "la terrestre", y te sirve la Tierra de la mano a la mano,

20 con espiga y horno, cepa y lagar. La casa y el jardín cruzan los niños; ellos parten tus ojos yendo y viniendo; sus siete nombres llenan tu boca, los siete donaires sueltan tu risa

25 y te enredas con ellos en hierbas locas. o te caes con ellos pasando médanos.

Gracias por el sueño que me dio tu casa, que fue de vellón de lana merino; por cada copo de tu árbol de ceibo ${ }^{6}$,

30 por la mañana en que oí las torcazas ${ }^{7}$;

\footnotetext{
3 Victoria Ocampo (1890-1979), escritora argentina, ensayista y editora de la revista Sur.

${ }^{4}$ Referencia alusiva a su estancia durante algunas semanas en Villa Victoria, casa de verano de la escritora, en Mar del Plata, en abril de 1938, donde escribió este recado.

5 Tala, en todas las ediciones de Editorial Losada: pasos.

${ }^{6}$ Ceibo 'Arbol americano, de la familia de las papilionáceas, notable por sus flores de cinco pétalos, rojas y brillantes, que nacen antes que las hojas, que son lanceoladas, verdes por la cara superior y gríseas por el envés. Su fruto, de unos $15 \mathrm{~cm}$ de largo, es peludo y con semillas ovoides. Tiene diferentes nombres según la región en que se cría'.

7 Tala 1938: que fue de vellón de lana merino;/ por toda hora en que olí alhucema,/por la mañana en que oí torcazas.
} 
por tu ocurrencia de "fuente de pájaros"8, por tanto verde en mis ojos heridos,

y bocanada de sal en mi aliento:

por tu paciencia para poetas

35 de los cuarenta puntos cardinales...

Te quiero porque eres vasca y eres terca y apuntas lejos, a lo que viene y aún no llega; y porque te pareces a bultos naturales:

40 a maíz que rebosa la América rebosa mano, rebosa boca-, y a la Pampa que es de su viento y el alma que es del Dios tremendo...

Te digo adiós y aquí te dejo,

45 como te hallé, sentada en dunas. Te encargo tierras de la América, ¡a ti tan ceiba ${ }^{9}$ y tan flamenco, $\mathrm{y} \tan$ andina y tan fluvial y tan cascada cegadora

50 y tan relámpago de la Pampa!

Guarda libre a tu Argentina el viento, el cielo y los trojes; libre la Cartilla ${ }^{10}$, libre el rezo, libre el canto, libre el llanto.

55 el pericón y la milonga, libre el lazo y el galope ${ }^{11}$ ¡y el dolor y la dicha libres!

Por la Ley vieja de la Tierra; por lo que es, por lo que ha sido,

60 por tu sangre y por la mía, ipor Martín Fierro ${ }^{12}$ y el Gran Cuyano ${ }^{13}$ y por Nuestro Señor Jesucristo!

\footnotetext{
${ }^{8}$ V. O. ha hecho en su jardín de Mar del Plata una fuentecita mínima de piedra donde beben los pájaros. Y la alimenta... Nota de la autora.

${ }^{9}$ Ceiba, 'Arbol americano bombacáceo, de 15 a $30 \mathrm{~m}$ de altura, de tronco grueso, ramas rojizas, flores rojas tintóreas y frutos de 10 a $30 \mathrm{~cm}$ de longitud, que contienen seis semillas envueltas en una especie de algodón'.

${ }^{10}$ Cartilla, 'cuaderno pequeño, impreso, que contiene las letras del alfabeto y los primeros rudimentos para aprender a leer'.

11 Tala 1938: libre el lazo, libre el galope: / ¡el dolor libre, la dicha libre!

12 Personaje del poema gauchesco del mismo nombre.

13 Nombre popular chileno de José de San Martín, nuestro héroe común. Nota de la autora.
} 
